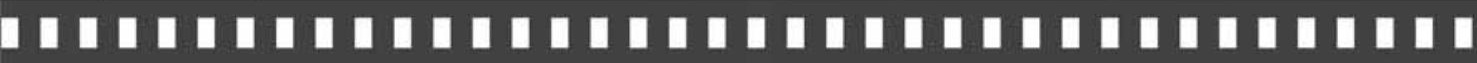 Conhecimento de mundo e leitura de imagem: um estudo sobre a intertextualidade na fotografia publicitária

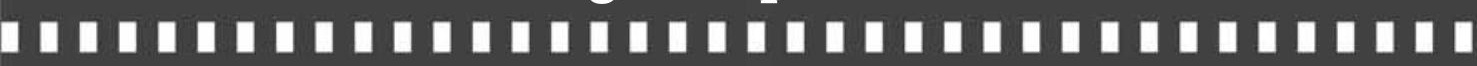

Maranúbia Pereira Barbosa-Doiron 


\title{
Conhecimento de mundo e leitura de imagem: um estudo sobre a intertextualidade na fotografia publicitária
}

\author{
World knowledge and image reading: a study about \\ intertextuality on publicity photography
}

Maranúbia Pereira Barbosa-Doiron*

\begin{abstract}
Resumo: Este estudo tem como proposta analisar a intertextualidade em fotografias publicitárias. A intertextualidade, segundo pressupostos teóricos da Linguística Textual, é entendida como a relação, direta ou indireta, entre os textos, e se constitui em um recurso cada vez mais utilizado em publicidade. Para que a propaganda, de natureza essencialmente persuasiva, produza efeitos de sentido, é necessário que haja uma boa parcela de conhecimento partilhado entre produtor e leitor. O produtor espera que o conhecimento de mundo do leitor possa lhe proporcionar embasamento para que compreenda não apenas o dito explícito na superfície textual, mas, também, e sobretudo, o implícito e o subentendido. Nas imagens da campanha publicitária aqui analisada, da grife francesa Louis Vuitton, o conhecimento de mundo se revela fundamental para uma leitura crítica e aprofundada.
\end{abstract}

Palavras-chave: Linguística textual; intertextualidade; imagem.

\begin{abstract}
This study aims to analyse the content of intertextuality ob publicity photography. According to textual linguistic theoretical premises, intertextuality is understood as the relation - direct or indirect - between texts, and its use as a resource on publicity has been rising substantially. In order to produce meaning effects on advertisement and its persuasive feature, it is necessary a common knowledge among producers and readers. The producer hopes that the reader's world knowledge can provide basis to understand not only the explicit message on the text surface, but also and mainly the implicit and implied. On Louis Vuitton publicity campaign studied here, the world knowledge is fundamental to develop a critic and profound review.
\end{abstract}

Keywords: Textual linguistic; intertextuality; image.

* Graduada em Comunicação Social - Jornalismo, pela Universidade Estadual de Londrina (UEL). Mestre em Estudos da Linguagem pela referida instituição. Cursou a disciplina Dialetologia e Geolinguística como estudante especial de doutorado na área de estudos citada. E-mail: maranubiapereira@hotmail.com . 


\section{Introdução}

Este artigo apresenta o estudo de algumas fotografias utilizadas em uma campanha publicitária, analisada sob os pressupostos teóricos da linguística textual, com especial ênfase na intertextualidade. O corpus consiste de uma série de propagandas lançada a partir de agosto de 2007, com abrangência internacional, para a grife francesa Louis Vuitton, tradicional fabricante de malas e acessórios de viagem. A campanha, denominada Voyages, criada pela agência multinacional Ogilvy \& Mather, foi divulgada em revistas, voltadas, principalmente, a um público de alto poder aquisitivo, tendo sido também veiculada em grandes jornais de diversos países, como o francês Le Monde, o americano The New York Times, o inglês The Times, entre os mais importantes, além de sites.

No Brasil, as propagandas circularam na Veja, Caras, Exame, Folha de S. Paulo, O Estado de São Paulo, Jornal do Brasil, dentre as publicações mais renomadas. Analisamos aqui seis imagens, das quais participaram personalidades da política, esporte e cultura, colhidas pela fotógrafa norte-americana Annie Leibovitz. Tomando como base os estudos em linguística textual, buscamos apontar, no referido corpus, os intertextos que nele permeiam, com vistas a enfatizar a relevância do conhecimento de mundo para uma leitura crítica de textos imagéticos.

\section{Da fundamentação teórica}

Em linguística textual, como é denominada a disciplina que se ocupa dos estudos textuais, todos os textos, tanto os verbais quanto os nãoverbais, aqui entendidos como forma de expressão humana, não são considerados produções construídas ao acaso. Ao contrário, os textos primam por serem dotados de extrema intencionalidade.

Nesse jogo que caracteriza a interação humana, existirão sempre duas instâncias. A primeira é a do produtor, que pode ser o escritor, o 
fotógrafo, o pintor, o falante, que quer convencer seu destinatário de algo que lhe convém, e para isso lançará mão de diversas estratégias linguísticoargumentativas, no caso do texto verbal. Em se tratando de textos nãoverbais, nos quais se insere a fotografia, o produtor empregará elementos de ordem visual/plástica, tais como a composição da luz, as cores, o contraste, a simetria, a perspectiva, entre outros. O destinatário - que pode ser o leitor, ouvinte ou observador - procurará estabelecer no texto significação e coerência, partindo de dados disponibilizados pelo produtor e ativando seu próprio conhecimento de mundo. Esse querer-convencer o destinatário, em linguística textual, é chamado de intencionalidade, um fator de textualidade que mantém uma relação estreita com a argumentatividade. Quando mencionamos argumentatividade queremos dizer que não existe neutralidade nos textos, e que esses não serão jamais uma cópia do mundo, visto que o produtor recria um mundo próprio a partir de suas convicções, experiências, crenças e valores.

No ato mesmo de construir a persuasão, o produtor do texto, qualquer que seja sua natureza, conta, necessariamente, com o conhecimento partilhado, ou seja, é preciso haver entre destinador e destinatário uma boa parcela de conhecimentos em comum. Segundo Koch e Travaglia (2004, p.77), quanto maior for o grau de completude de informações entre ambos, menor será a necessidade de explicitude do texto. Quando o produtor, propositadamente, resgata textos anteriores, e leva seu destinatário a reconhecer traços de outras produções, tem-se um fenômeno linguístico denominado intertextualidade.

De acordo com Beaugrande e Dressler (1997), a intertextualidade ocorre quando um texto retoma o conteúdo de outro; quando ambos, de certa forma, “dialogam” entre si. Bakhtin (1988) foi quem primeiro teorizou acerca da intertextualidade dando-lhe o nome de dialogismo, fenômeno em que se percebem no texto ecos de diversas vozes, entrecruzadas no espaço da enunciação.

Para Koch (2004, p.145), “a intertextualidade é a presença do outro naquilo que dizemos ou escrevemos”. Esse recurso argumentativo, complementa a autora, pode ser explícito, quando o produtor cita o autor 
do intertexto, ou implícito, quando não há citação direta, se a menção for apenas sugerida. De todo modo, em ambos os casos o destinatário terá que ativar na mente o texto-fonte. Kristeva (2005, p.68), ao tratar do conceito de intertextualidade, acrescenta que “todo texto se constrói como um mosaico de citações, todo texto é absorção e transformação de textos”. Ainda em Koch (2004, p.145) encontra-se a concepção de intertextualidade ou polifonia em sentido amplo, "constitutiva de todo e qualquer discurso, e a intertextualidade stricto sensu, atestada, necessariamente, pela presença de um intertexto”.

Sant'Anna (1985) chama de intertextualidade de semelhanças os textos que reafirmam intertextos, reiteram seus conteúdos proposicionais e orientam o leitor para tirar suas conclusões em conformidade com o texto-fonte. Em resumo, eles aderem aos ditos no texto original. Mussalim e Bentes (2005, p.271) argumentam que os intertextos "revelam um pouco de nossa habilidade de brincar com a linguagem, de nos utilizarmos dela com grande desenvoltura para conseguirmos os efeitos desejados”. A intertextualidades das diferenças, conforme Sant'Anna (1985), consiste em retomar o que foi dito para propor uma leitura diferenciada e/ou contrária ao texto original. Isso acontece especialmente nos casos em que o produtor quer parodiar, ironizar ou criticar: ao subverter o texto-fonte, o autor busca produzir determinados efeitos de sentido.

A intertextualidade, então, está relacionada a fatores que fazem a interpretação de um texto depender de outros para que seja compreendido. Um discurso não surge do nada, num aparente descomprometimento ante os demais. Ao contrário disso, ele se constrói por meio de um já-dito, e nesse debruçar-se sobre outros discursos ele tomará (ou não) uma posição. Há muitos textos que só fazem sentido quando o leitor/ouvinte consegue estabelecer uma relação com um terceiro, e este funcionará como contexto. Lembremos sempre que isso se dá nos textos verbais e não-verbais.

A presença da intertextualidade em textos não-verbais é um recurso cada vez mais empregado, notadamente, em fotografias utilizadas em propagandas. Nesse caso, o produtor procura se remeter a imagens ligadas a eventos, pessoas ou situações, e espera contar com a bagagem de 
conhecimento de seu destinador, para que esse possa construir efeitos de sentido a partir do que tem diante de si.

Quanto mais vasto o repertório de conhecimentos do sujeito, maiores serão suas possibilidades de leitura. O conhecimento de mundo é adquirido vida afora, advém do acúmulo de experiências, renova-se e se reformula nos contatos que as pessoas travam umas com as outras cotidianamente. De acordo com Koch e Travaglia (2004, p.76), “é a partir dos conhecimentos que temos que vamos construir um modelo de mundo representado em cada texto - é o universo (ou modelo) textual”. Ao se deparar com um texto qualquer, o leitor/observador/ouvinte aciona seu acervo de conhecimentos e poderá (ou não) preencher as lacunas por meio de inferências. É o caso da série de propagandas que analisamos a seguir, em que será necessária a ativação do conhecimento de mundo para uma leitura substanciosa.

\section{Da intertextualidade em imagens de propaganda}

A propaganda conta com o conhecimento de quem lê, cria textos direcionados a públicos específicos, e espera desses leitores, uma clientela em potencial, a capacidade de depreender significações que subjazem à superfície textual. Na campanha publicitária Voyages, da grife francesa Louis Vuitton, o produtor, ao se valer da intertextualidade implícita, orienta o leitor de modo que ele possa estabelecer elos entre imagem/texto e o produto à venda - as malas.

Nas propagandas ora analisadas, a intertextualidade é implícita, sendo fundamental que o leitor, a partir de conhecimentos prévios, faça várias inferências, operações que possibilitam o estabelecimento de uma relação entre a superfície textual e o que está subentendido, podendo ele, dessa forma, empreender uma leitura mais rica e aprofundada do texto-imagem.

Vejamos, em primeiro lugar, o texto-mote da campanha, disponível no site da Louis Vuitton. 


Voyages
Qu'est-ce que c'est un voyage?
Ce n'est pas un départ.
Ce n'est pas une destination.
C’est un parcours. Une découverte.
Une découverte de soi-même.
Certains voyages nous mettent face à nous-
même.
Voyage-t-on pour découvrir le monde ou
pour se redécouvrir?
Est-ce les hommes qui font les voyages ou
les voyages qui font les hommes?
Le voyage, c'est la vie.
Autant de voyages, autant d'émotions.

\section{Viagens $^{1 *}$}

O que é uma viagem?

Viagem não é partida.

Viagem não é destinação.

Viagem é um percurso. Uma descoberta.

Uma descoberta de si mesmo.

Certas viagens nos colocam face a face a nós mesmos.

Viaja-se para descobrir o mundo ou para se redescobrir?

São os homens que fazem as viagens ou as viagens que fazem os homens?

Viagem é vida.

Quanto mais viagens, mais emoções.

Fonte: Louis Vuitton (2009)

O produtor constrói sua argumentação a partir de uma associação: viagem - descoberta. Mas, viajar, segundo o texto, não se restringe pura e simplesmente a partidas e chegadas. Viagens são percursos que conduzem a descobertas, e essas descobertas vão além de lugares geográficos. As viagens, argumenta o produtor, colocam o viajante de frente para si mesmo na medida em que possibilitam momentos de incursões pessoais. O produtor questiona se são os homens que fazem as viagens ou se são elas que fazem os homens, dando ele próprio a resposta: “viagem é vida”, ou seja, é no ato, no processo mesmo de se deslocar de um lugar a outro que os homens viverão mais e poderão conhecer outras facetas de si mesmos. O ir e vir das viagens implica em viver emoções.

Ora, a grife Louis Vuitton vende malas, só que essas malas não se destinam nem a viagens e muito menos ainda a viajantes ordinários: elas são acessórios especiais e acompanham pessoas que procuram viver momentos à altura. A ideia estabelecida por detrás do discurso não é outra que não essa: as malas Louis Vuitton são as melhores companheiras de viagem. As intenções do produtor em sedimentar

\footnotetext{
${ }^{1}$ Esta tradução, bem como as demais que aparecem ao longo do texto, é de nossa autoria.
} 
essa ideia não param por aí. O texto-mote abre a campanha e a partir desse ponto introduz o leitor rumo ao entendimento das propagandas que virão em seguida.

Vejamos a primeira delas, aqui chamada de figura 1. Temos a fotografia de um homem elegantemente vestido, sentado no banco de um automóvel que lembra uma limusine, dado o grande espaço interior. Ao lado do homem, livros e jornais displicentemente arranjados e uma valise de tamanho médio. A luz incide sobre ela e faz ver a clássica logomarca da Louis Vuitton. Sentado no banco traseiro do veículo, de onde se infere que há um motorista que o conduz, o homem passeia o olhar, pensativamente, sobre o muro ao longo da rua. Um tanto mal conservado, pichado, mas robusto, o muro ladeia a imagem, em perspectiva. A presença do muro, marcante, está refletida no vidro do carro. Abaixo da fotografia lê-se: A journey brings us face to face with ourselves. Berlim Wall, returning from a conference ${ }^{2}$. (Uma viagem nos coloca face a face com nós mesmos. Muro de Berlim, voltando de uma conferência).

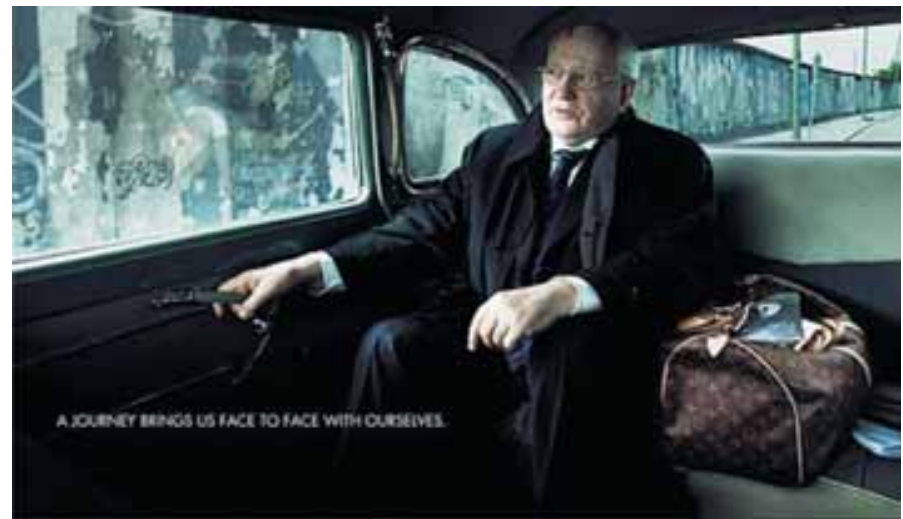

Figura 1 - Uma viagem nos coloca face a face com nós mesmos Fotografia: Annie Leibovitz

Fonte: Louis Vuitton (2009)

${ }^{2}$ As frases completas que acompanham as fotografias analisadas estão disponíveis no site www.louisvuitton.fr. 
O leitor que possuir um amplo conhecimento de mundo irá reconhecer no homem da fotografia o russo Mikhail Gorbachev, expresidente da extinta União Soviética, mentor da perestroika (reconstrução, em russo) e da glasnost (transparência, abertura), medidas políticas que literalmente abriram caminho para a entrada do capitalismo no país, a partir de 1985. O Muro de Berlim, ícone representativo da separação das duas Alemanhas, veio abaixo em novembro de 1989, e com ele a derrocada do socialismo nos países que ficavam além da Cortina de Ferro, ou seja, concebia-se uma divisão ideológica entre os países - capitalistas liderados pelos EUA de um lado, e comunistas, cujo domínio cabia à União Soviética, de outro. Gorbachev, ao passar em frente a uma parte do muro que permaneceu de pé, parece rememorar todo esse momento histórico do qual foi o principal articulador.

De posse desses conhecimentos, o leitor, ainda que não reconheça de imediato o rosto do político russo, já que à época do lançamento da campanha publicitária, em 2007, ele já não frequentava a mídia com tanta assiduidade, poderá fazer inferências e estabelecer a relação entre os principais elementos textuais - a imagem do muro e a frase "uma viagem nos coloca face a face com nós mesmos". Gorbachev está de frente para sua própria história. O intertexto, nesse caso, é todo o contexto político implícito na propaganda. O produtor, com toda a sutileza, insere ainda na imagem uma informação que não passará despercebida ao leitor mais atento: o fato de Gorbachev portar uma valise Louis Vuitton, um bem de consumo caro, indica que um dos valores intrínsecos ao mundo ocidental, o capitalismo, sobrepujou o socialismo.

Passemos à análise da figura 2. A imagem é de uma mulher sentada sobre duas malas na plataforma de uma estação de trem. O comboio, de um modelo antigo, parece ter acabado de chegar ou se prepara para partir, pois lança no ar uma fumaça pálida. Há um quê de melancolia no cenário, um toque clássico dado pela locomotiva, lembrando o famoso trem Orient Express, que faz a linha Europa-Ásia. A atmosfera é literalmente cinematográfica, reforçada pela presença do holofote sobre o tripé e os cabos de uma câmera que não aparece na fotografia. A atenção do leitor se volta toda para a mulher: loura, elegante, olhar indiferente, 
casaco preto, bolsa dependurada no braço, pernas cruzadas, salto alto, ela parece esperar. Mas, esperar pelo quê, por quem? Há alguns elementos textuais que podem fornecer as respostas.

Acompanha a imagem o seguinte enunciado: Sometimes, home is just a feeling. Take three, last day of shooting. Paris, Gare Austerlitz. (Algumas vezes, a casa é apenas um sentimento. Tomada três, último dia de gravação. Paris, estação de Austerlitz). Temos então alguns dados importantes: a cidade onde fica a estação de trem - Paris - e o holofote e cabos indicando que no local está sendo rodado um filme. Entretanto, o produtor não diz quem é a mulher, mas o nome dela está lá, implícito no contexto. O leitor reúne todos os elementos de que dispõe - explícitos e implícitos - e infere que se trata da atriz francesa Catherine Deneuve, a eterna Belle de jour ( a bela da tarde), personagem que marcou sua carreira, sempre associado à sua imagem.

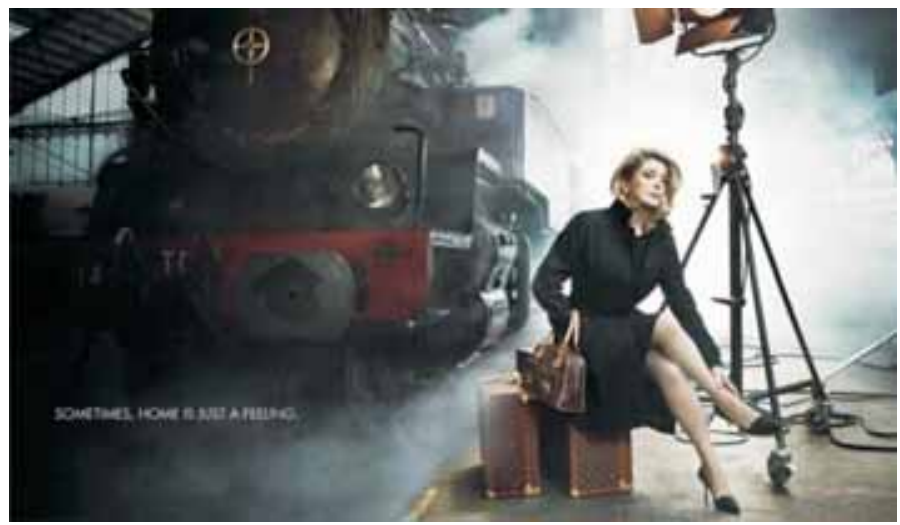

Figura 2 - Algumas vezes, a casa é apenas um sentimento Fotografia: Annie Leibovitz

Fonte: Louis Vuitton (2009)

Mas, por que seria Catherine Deneuve e não Brigitte Bardot, por exemplo, se ambas são francesas, louras e igualmente célebres? Em Belle de jour (1967), filme de Luis Buñuel, a personagem, insatisfeita no casamento, prostitui-se durante as tardes, e acumula experiências sexuais breves. Seus amantes se sucedem, são como viagens, idas e vindas fugazes, 
e a casa para na qual retorna depois dos encontros furtivos é o local onde tem tudo o que se necessita materialmente, mas abriga suas culpas e frustrações. O casamento, representado pela casa, não passa de um sentimento tumultuado, sinônimo de infelicidade. A frase Sometimes, home is just a feeling, remete ao filme e à Deneuve, a atriz que o interpretou. Somando tudo - cenário de filme, estação de trem, loura de olhar blaséinfere-se que seja a atriz Catherine Deneuve. O intertexto, implícito, será claro para quem viu o filme, para quem conhece a atriz e tem os demais dados de memória.

Em seguida, temos a figura 3. Vemos um casal, em primeiro plano, deitado, numa cena que denota pura tranquilidade. Seus pertences estão sobre uma pequena mesa e uma cadeira. Há uma série de objetos, típicos da vida moderna: agenda, jornal dobrado, câmera fotográfica digital, computador portátil, chaves, óculos escuros, copos, uma valise e uma pequena mala, ambas entreabertas. Tem-se a impressão de que o homem e a mulher acabaram de chegar, que descansam por alguns instantes, que ainda nem desfizeram suas bagagens. Junto à imagem consta este texto: Is there any greater journey than love? Room 27, late june, New York. (Há alguma viagem maior que o amor? Quarto 27, junho último, Nova Iorque).

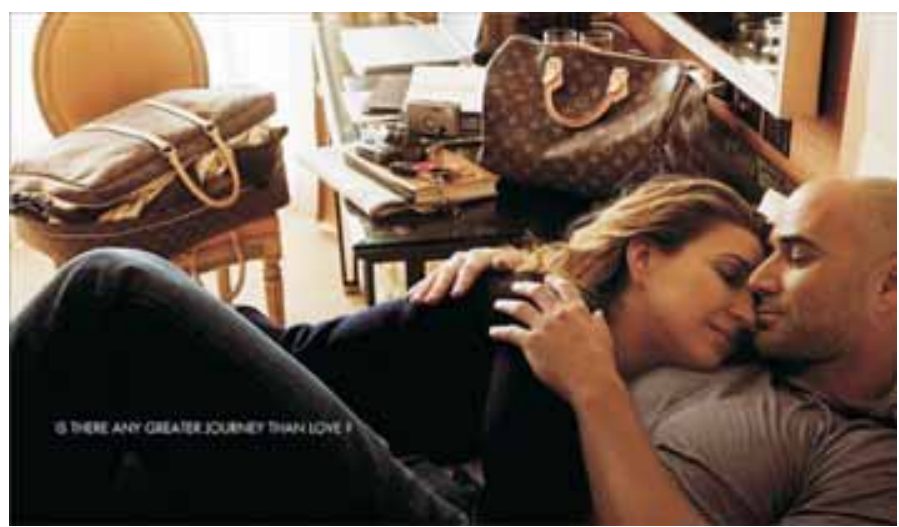

Figura 3 - Há alguma viagem maior que o amor?

Fotografia: Annie Leibovitz

Fonte: Louis Vuitton (2009) 
Trata-se de um casal jovem e saudável, seus rostos e corpos levam a pensar em juventude e vitalidade. A imagem do homem, máscula, mas também terna e protetora, atrai o olhar. Ele tem a barba por fazer, a cabeça raspada; reparemos que a camiseta que ele usa, colada ao peito, deixa ver com muita nitidez as linhas definidas de seu tórax; na cor cinza, contra os tons escuros do jeans, a camiseta direciona o olhar para o peito do homem, revelando intencionalmente suas formas; sob o jeans, sobressai-se a coxa, o joelho se evidencia pela réstia de luz sobre uma parte do tecido. Mas são suas mãos que se destacam. A luz recai sobre elas, dá-lhes um aspecto ainda mais potente, avolumam-se, contrastadas pelo tecido preto da roupa da mulher. Os dedos estão entreabertos, as mãos são grandes, como mãos de trabalhadores braçais, de estivadores. Entretanto, o homem não parece se enquadrar nessa categoria trabalhista, o cenário onde ele está não condiz com isso, não há elementos que indiquem ser ele oriundo da classe operária. Homens que vivem em condições sociais mais privilegiadas, possuindo o mesmo vigor físico que um trabalhador braçal, são vistos mais frequentemente no esporte. As mãos do homem da fotografia levam a pensar que ele poderia, então, pertencer a modalidade esportiva que trabalha muito essa parte do corpo: o tênis. Se for o homem da fotografia um tenista, por que razão o produtor não deslocou para o cenário raquetes, bolas ou outros materiais utilizados nesse esporte? O produtor, no lugar desses elementos, apresenta uma mulher, que repousa, serena, sobre o peito do homem. Que não se engane o leitor, ela não está ali sem razão.

O tenista conhecido por muitos títulos no currículo é o norteamericano André Agassi, que ganhou as manchetes de jornais de todo o mundo pelos campeonatos conquistados, e também por outra razão, mas de cunho privado. Agassi é lembrado pelo casamento, em 2001, com a tenista alemã Steffi Graf, um dos maiores nomes da história desse esporte. Não se tem notícia, no tênis, de outro casal que acumule tantos Grand Slam em suas carreiras. Naturalmente, o leitor só poderá chegar a essas conclusões se possuir conhecimentos prévios que lhe permitam relacionar texto verbal e imagem. O produtor da fotografia fez a retomada de todo o 
contexto do qual fazem parte Agassi e Graf: beleza plástica, força, modernidade (nos objetos), e amor, a razão de estarem juntos.

A figura 4 mostra a imagem de um guitarrista num quarto. Seu visual despojado (blusão de couro, anel, pulseira, olhos delineados em preto) contrasta com o quarto, sóbrio, paredes decoradas em gesso, em tons pastéis, com cadeira de estofo acetinado, cortinas pesadas e quadro clássico. Em cima da cama, uma mala, e sobre ela uma xícara de chá, colherinha, um livro aberto, uma lupa - esta última, aliada de quem tem problemas em ler letras de pequeno formato. Ao fundo se vê o aparelho de chá sobre uma poltrona de tecido adamascado. A luz do abajur é atenuada por um véu preto. Um olhar mais apurado aponta para o que parece ser um pequeno crânio, à direita na fotografia, debaixo do abajur. O cenário parece casar perfeitamente com a figura de um guitarrista, melhor ainda, de um roqueiro.

Muitos desses artistas cultivam a imagem de durões, de rebeldes, e com isso alimentam o imaginário popular, que sempre pensam neles como pessoas irreverentes. Acompanha a propaganda uma frase que reforça essas inferências: Some journeys cannot be put into words. New York, 3 pm. Blues in C. (Algumas viagens não podem ser expressadas em palavras. Nova Iorque, três da manhã. Blues em dó). O intertexto, implícito nessa propaganda, é o próprio rock e todos os frames que ele ativa, isto é, o conhecimento de senso comum sobre um conceito central qualquer. Pode-se inferir também, nesse exemplo específico, tomando por base conhecimentos estereotipados, chamados em linguística textual de scripts, que o rock casa bem com subversão, rebeldia, transgressão de tudo daquilo que a sociedade considera convencional.

Quem seria o roqueiro da propaganda? O nome dele não está escrito com todas as letras na fotografia, pelo menos não de maneira explícita. O texto visual/verbal fornece algumas pistas: os roqueiros, pela imagem rebelde que é veiculada na mídia, são associados a bebidas mais encorpadas, raramente são vistos por aí tomando chá, a não ser que sejam britânicos, apreciadores dessa infusão; os roqueiros costumam encerrar suas carreiras ainda jovens, pois o estilo não combina muito com cidadãos maduros, e o homem da foto parece ser sexagenário - vêem-se as rugas 
de seu rosto, os fios grisalhos de seus cabelos por trás da tiara. No cenário do rock pesado mundial, são poucos os músicos que continuam na ativa depois da maturidade, podendo ser citados os ingleses David Bowie e Ozzy Ozbourne, o mexicano Carlos Santana, entre os nomes mais significativos. Além desses, os roqueiros que mantêm a carreira com o mesmo vigor da década de sessenta são, nada mais nada menos, que os britânicos Rollings Stones, condecorados com o título de Sir pela rainha da Inglaterra.

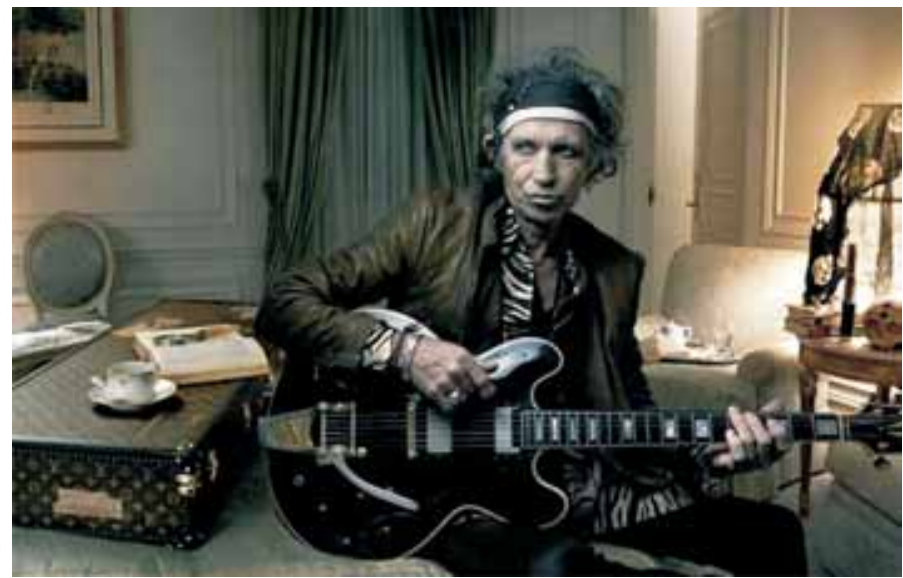

Figura 4 - Algumas viagens não podem ser expressadas em palavras Fotografia: Annie Leibovitz Fonte: Louis Vuitton (2009)

O músico da fotografia não parece ser Mick Jagger, o vocalista, mais lembrado pelos lábios carnudos que, inclusive, inspiraram o artista da pop-art, Andy Warhol, a criar a imagem que ficou sendo uma espécie de logomarca do grupo: uma enorme boca vermelha com a língua de fora. O roqueiro da propaganda da Louis Vuitton, então, é Keith Richards, o mais controvertido dentre os Stones. A viagem a qual ele se refere, aquela que não pode ser traduzida em palavras, é a que fazia pelo mundo das drogas, quando era mais jovem. Richards tem um histórico memorável ligado à heroína e ao álcool, mas daqueles anos loucos ele só conserva mesmo a cara de mau. Hoje o roqueiro britânico 
toma chá preto, enquanto compõe, sossegado, blues de madrugada na penumbra de um quarto de hotel.

Em seguida, a figura 5. Essa propaganda da campanha Voyages retrata um homem e uma mulher no campo. A luz é tênue, típica de fins de tarde. Ele fala qualquer coisa, parece explicar algo importante, gesticula, enquanto ela, compenetrada, ouve. Ambos estão relaxados, ela está estirada na grama, descalça, bastante à vontade, os dois parecem íntimos. O homem é mais velho que a moça, ela o olha de modo respeitoso, com admiração. Ele se porta como um pai falando com a filha, e mesmo a posição em que se encontra, sentado, dedo em riste, induz a isso.

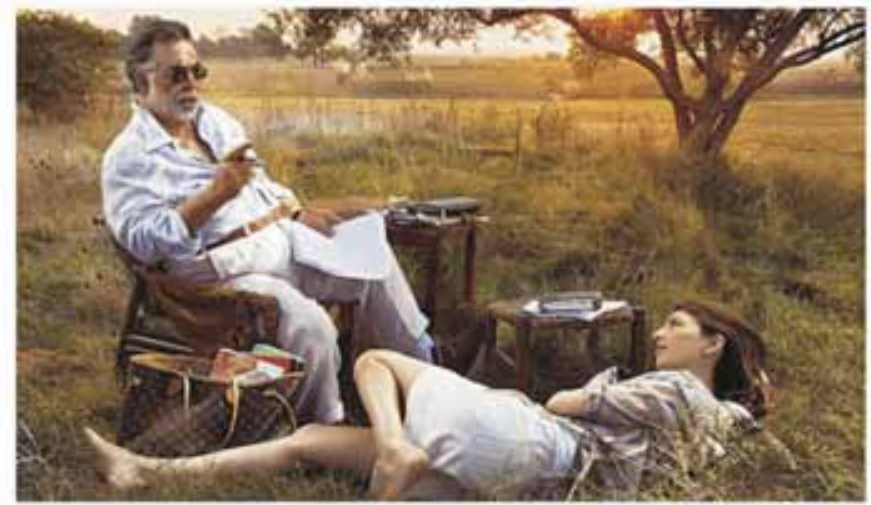

IOUIS VUITTON

Figura 5 - Uma viagem sempre começa por uma bela história

Fotografia: Annie Leibovitz

Fonte: Louis Vuitton (2009)

Mas, quem seriam eles? Vejamos o que o texto explicita: o homem tem ao lado uma valise Louis Vuitton com umas revistas, e segura umas folhas de papel; aparecem na cena uma pequena mesa com uma agenda em cima, um tamborete, em material que combina rusticidade e classe. A cadeira onde está sentado o homem não é convencional. Ela tem o encosto cruzado, é dobrável, tal e qual as cadeiras de diretor de cinema, só que mais sofisticada.

A frase junto à imagem é mais um dado importante na compreensão de todo o texto: Un voyage commence souvent par une belle histoire. 
7 heures du soir, Buenos Aires, Argentine. (Uma viagem sempre começa por uma bela história. 7 horas da noite, Buenos Aires, Argentina). $\mathrm{O}$ produtor indica que o homem da fotografia conta uma história à moça, $\mathrm{e}$ toda a situação comunicativa, verbal e não-verbal (o posicionamento dos objetos em cena, a tonalidade da luz, o enquadramento dos dois), leva a crer que ele seja cineasta. O cinema, à sua maneira e a partir de um determinado enredo, convida o público a embarcar em viagens.

O homem da fotografia, Francis Ford Coppola, diretor de filmes notáveis como “O Poderoso Chefão”, “Apocalipse Now”, "Drácula de Bram Stocker”, “O Selvagem da Motocicleta”, ensina a filha, Sophia Coppola, como fazer isso: contar uma história. Logicamente, toda essa leitura, ainda que contenha elementos que levem a se pensar que o contexto seja o cinema, só estará acessível àqueles que reconhecerem a figura do diretor. Todavia, ainda que isso não ocorra, a imagem não perde sua essência, que é a de enlevar, a partir da atmosfera algo idílica, o leitor, e induzi-lo a pensar que a dupla fotografada, quem quer que seja ela, faz parte de uma elite poderosa o bastante para poder comprar mercadorias Louis Vuitton.

Finalmente, a última propaganda da série, lançada no final de 2008.

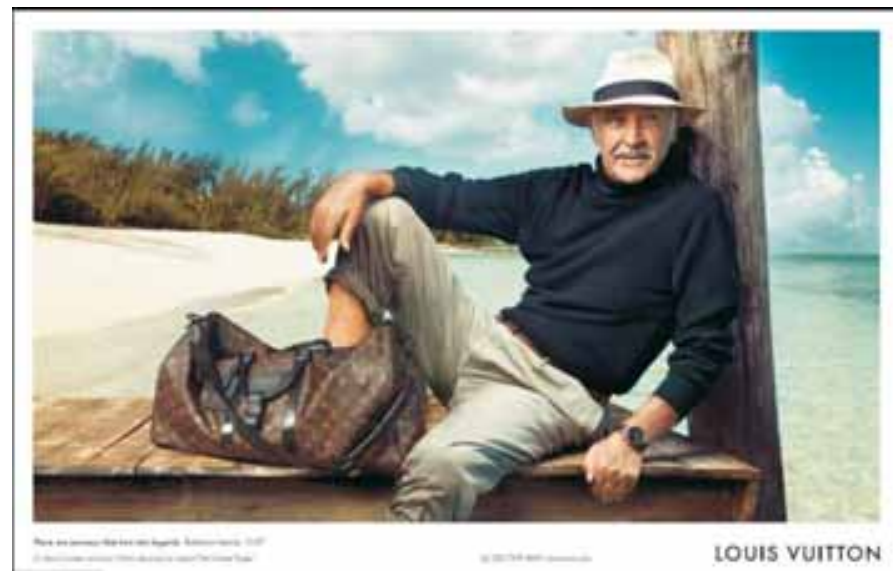

Figura 6 - Existem viagens que se transformam em lendas

Fotografia: Annie Leibovitz

Fonte: Louis Vuitton (2009) 
Na fotografia, um homem está sentado em uma plataforma de madeira à beira-mar. Recostado em um pilar, chama a atenção o fato de ele estar vestido de maneira clássica em um lugar que pede um figurino mais descontraído. Calça de sarja, cinto marrom, pulôver azul-marinho de gola alta e chapéu Panamá, relógio de pulso esportivo de boa qualidade: ele prima pela elegância. Não dá para saber se ele está usando algum calçado ou se está descalço, já que a perna direita está posicionada atrás de uma valise e a esquerda, estirada, fica fora do campo de visão do leitor. A valise de alças de couro, estrategicamente pousada ao pé do homem, da marca Louis Vuitton (vê-se o logotipo da marca), parece conter pouco volume. A valise e a calça do homem, arregaçada, estão molhadas. Atrás dele, a areia branca e a vegetação natural denotam ser a praia deserta ou pouco frequentada. O produtor captou as cores de modo a enlevar o observador: a água é translúcida, a linha do horizonte ao fundo, à direita, separa os dois tons de azul: em cima, o céu pincelado por nuvens espessas, e em baixo, uma tonalidade que se aproxima do esverdeado. Enquadrando a fotografia, a seguinte frase: There are journeys that turn legends. Bahamas Islands, 10:07. (Existem viagens que se transformam em lendas. Ilhas Bahamas, 10:07).

Reunidas essas informações preliminares, vejamos o que a imagem tem a dizer. O homem fotografado não é jovem, pode-se ver pelas costeletas brancas, pelos vincos das maçãs do rosto, pela aparência da pele de sua mão direita estendida sobre o joelho. Em contrapartida, ele ostenta um corpo esguio e atlético para a idade: o pulôver, por dentro da calça, sugere um abdome enxuto, fisicamente em forma. O homem olha para longe, está atento, como a espreitar, ou a esperar por algo. Seu rosto é familiar e, por certo, muitos leitores irão reconhecer de imediato o ator escocês Sean Connery.

Saber quem é o garoto-propaganda, contudo, não explica a razão de sua presença naquele cenário específico. Por que Sean Connery teria posado para a grife Louis Vuitton? Pode-se cogitar que pelo fato da campanha Voyages estar focada em celebridades, Connery foi escolhido por ser mundialmente famoso, por já ter sido agraciado com o título de 
Sir pela rainha da Inglaterra, apesar de sua militância em favor da independência da Escócia, sua terra natal. Além dessas inferências, a imagem tem mais a revelar, começando pela frase: existem viagens que se transformam em lendas. Ao mencionar "lendas", o leitor mais atento depreende que o ator Sean Connery encarnou por mais de uma década um dos personagens mais carismáticos da história do cinema. Não serão poucos os que irão associar a figura de Connery a de James Bond, o agente secreto 007 a serviço de Sua Majestade, a rainha da Inglaterra. Personagem criado pelo escritor inglês Ian Fleming, Bond foi levado ao cinema pela primeira vez em 1962, no filme $O$ satânico Dr. No. Na trama, o espião britânico, incumbido de tirar de circulação um cientista que planeja destruir o programa espacial americano, chega a uma ilha no mar do Caribe. Em uma das cenas, o agente 007, dormitando num canto da praia depois de escapar de seus inimigos, é despertado pelo canto de uma mulher que emerge das ondas, corpo escultural, biquíni branco, faca de mergulho na cintura. Essa cena da bond-girl, representada pela atriz Úrsula Andrews, junto com James Bond na praia de areia branca figura como uma das imagens mais emblemáticas do cinema.

Feitas essas associações, pode-se inferir, então, que o ator Sean Connery está de volta à praia paradisíaca onde encontrou a moça do biquíni branco, inferência reforçada pela frase que fala em viagem e lenda. O produtor da imagem criou a cena de modo a conduzir o leitor a essa conclusão. Na fotografia não é o ator Sean Connery que se vê, e sim Bond, James Bond, um pouco mais envelhecido, mas sempre o mesmo olhar sedutor, sempre a mesma vivacidade, à espera que surja das águas sua eterna bond-girl.

Nas imagens aqui analisadas omitimos, propositadamente, alguns dos nomes das personalidades, apesar de que em todas as publicações nas quais a campanha Voyages foi veiculada os modelos estão devidamente nominados. Ao optarmos pela supressão de alguns nomes, quisemos demonstrar que mesmo sem identificá-las seria perfeitamente possível fazer as leituras aqui apresentadas. Contudo, as imagens, acompanhadas ou 
não da identidade dos fotografados, só produzem os efeitos de sentido desejados pelo produtor se o leitor puder contar com um conhecimento de mundo aprofundado.

Resta, por fim, discutir a questão daquele leitor inapto a empreender as inferências aqui sugeridas. De nossa parte, acreditamos que um conhecimento de mundo mais alargado subsidia o indivíduo de forma a escapar da superficialidade, o que não quer dizer, absolutamente, que sem bagagem de conhecimento não seja possível construir outras leituras. Defendemos a ideia de que os leitores têm suas individualidades e, certamente, muitos deles terão outras propostas baseadas em suas diferentes vivências, chegando a leituras nem sempre imaginadas pelo produtor.

\section{Considerações finais}

Como vimos, o emprego da intertextualidade implícita, um recurso cada vez mais frequente no discurso publicitário, requer do leitor um conhecimento de mundo consistente. Ao se referir a textos anteriormente produzidos, o produtor transmite ideologias, propaga ideias de toda ordem, reforça estereótipos, constrói e destrói conceitos. A propaganda, cada vez mais sofisticada na atualidade, não quer apenas vender coisas. Muito mais do que disso, ela se propõe a difundir valores inerentes ao consumismo, a reafirmar preceitos em vigor na sociedade capitalista.

Em se tratando de propagandas que fazem uso de textos ou imagens de caráter implícito, o reconhecimento do texto ou imagemfonte torna-se imprescindível para a produção dos efeitos de sentido concebidos pelo autor/enunciador, o que é reiterado por Koch (1997, p.46): "todo texto é um objeto heterogêneo que revela uma relação radical de seu interior com seu exterior; e desse exterior fazem parte outros textos que lhe dão origem, que o predeterminam, com os quais dialoga.” 
A campanha publicitária Voyages faz refletir sobre o fator interdiscursividade que, juntamente com a intertextualidade, diz respeito às vozes e, segundo Fiorin e Barros (2003, p.34), "à questão do discurso bivocal de que falava Bakhtin”. Com efeito, sob um texto ou um discurso ressoa outro texto ou outro discurso: sob a voz de um enunciador, a de outro". Para os autores, a interdiscursividade é inerente à constituição mesma do discurso. O discurso, complementam Fiorin e Barros (2003, p.34), "não é único e irrepetível, pois um discurso discursa outros discursos”. Em Voyages, o discurso veiculado pelas propagandas reproduz e difunde a ideologia do capitalismo, dos eventuais benefícios de estar aderido a ele, da necessidade de consumir produtos associados à elite.

Nas imagens aqui coletadas, o produtor espera que seu leitor/ consumidor possa identificar as pessoas fotografadas e os contextos relativos a elas, e associe tudo isso a um produto bem mais importante do que as malas: a marca Louis Vuitton.

A fotógrafa Annie Leibovitz soube bem aproveitar a imagem das personalidades fotografadas. A fotografia do político russo Gorbachev, sempre associado à queda do muro de Berlim, resume, de modo geral, os intertextos presentes nas demais imagens produzidas para a campanha Voyages. Leibovitz traz o intertexto para a fotografia: a imagem do muro, visto a partir de uma perspectiva horizontal, faz referência à linha histórica, ou seja, a todos os acontecimentos que, alinhados, culminaram na queda da construção em si e no sistema político que ele representava. Entretanto, Leibovitz, com sutileza, insere na imagem outro elemento que, aos olhos de um leitor mais perspicaz, não passa despercebido. O rosto de Gorbachev traz, além da mancha de nascença avermelhada no alto da testa (detalhe sempre explorado pelos fotógrafos), sinais de ligeira tensão, vê-se pelas sobrancelhas arqueadas. Pergunta-se: será que Leibovitz pensou a fotografia dessa forma? Talvez sim, mas pode ser também que Gorbachev, sabedor do peso de sua imagem para a história do século XX, não estaria tão à vontade quando da composição da cena. Há ainda um último detalhe que reforça essa dúvida: a mão do ex-presidente 
russo segurando a maçaneta do carro. O gesto pode ser entendido como natural, ou, ao contrário disso, a mão na porta indicaria uma eventual saída do veículo: Gorbachev é um homem imerso em símbolos do capitalismo, sem, contudo, desconsiderar de todo o antigo regime, ainda presente no muro do lado de fora. O intertexto na fotografia de Gorbachev, quaisquer que sejam as leituras que se façam, é sempre o contexto político.

Essa última consideração sobre a fotografia de Gorbachev vale também para as outras: a atriz Catherine Deneuve sob holofotes na estação de trem; Agassi e Graf deitados numa cama de um quarto de hotel; o Stone Keith Richard dedilhando a guitarra ao lado de um bule de chá; os Coppola, pai e filha, conversando numa pradaria; o ator Sean Connery emoldurado por uma praia de água cristalina. Em todas as imagens dessa campanha publicitária, além dos intertextos citados separadamente em cada uma das análises - política, esporte, rock e cinema - há um intertexto comum a todas: a viagem como acontecimento, seja ela geográfica, sentimental, bucólica ou nostálgica. Viagem é o elemento comum a todas as fotografias.

A intertextualidade nas fotografias estudadas põe em relevo os efeitos de sentidos que, possivelmente, foram pensados pelo produtor das imagens: o nome Louis Vuitton. A grife é a principal mercadoria à venda, é um bem de alto custo, muito mais caro do que as próprias malas, acessível apenas à classe $\mathrm{A}$.

Nas propagandas vistas aqui, o uso da intertextualidade implícita cumpre a função de remeter a um contexto específico - o mundo da elegância, do refinamento e do poder. O leitor é induzido a desejar não apenas as malas, mas poder viajar, passear de limusine, hospedar-se em hotéis luxuosos, desfrutar da beleza de ilhas paradisíacas, praticar esportes elitizados. O leitor crítico conclui que o dinheiro possibilita a compra de produtos de grife, constituindo-se no passaporte de entrada ao seleto clube das personalidades-modelos apresentadas: se até Gorbachev, que era comunista, rendeu-se ao luxo das malas Louis Vuitton, ícone do capitalismo, por que não nós também? 


\section{Referências}

BAKHTIN, Mikhail. Marxismo e filosofia da linguagem. São Paulo: Hucitec, 1988.

BEAUGRANDE, Robert de; DRESSLER, Wolfgang U. Introduction a la linguística del texto. Barcelona: Ariel, 1997.

FIORIN, José Luiz; BARROS, Diana Luz Pessoa de (Org.).

Dialogismo, polifonia, intertextualidade: em torno de Bakhtin. 2.ed. São Paulo: Edusp, 2003.

KOCH, Ingedore; TRAVAGLIA, Luiz Carlos. A coerência textual. São Paulo: Contexto, 2004.

KOCH, Ingedore. Introdução à linguística: trajetória e temas. São Paulo: Martins Fontes, 2004.

. O texto e a construção de sentidos. São Paulo:

Contexto, 1997.

KRISTEVA, Julia. Introdução à semanálise. São Paulo: Perspectiva, 2005.

LOUIS VUITTON. Univers Louis Vuitton. Disponível em:

<www.louisvuitton.fr> . Acesso em: ago. 2009.

MUSSALIM, Fernanda; BENTES, Anna Christina. Introdução à linguística. São Paulo: Cortez, 2005.

SANT’ANNA, Affonso Rommano de. Paródia, paráfrase e cia. São Paulo: Ática, 1985. 